\title{
Intubation using lidocaine, low dose rocuronium, remifentanil and propofol-what should we know?
}

\author{
Arsen Uvelin, MD · Snežana Stanisavljević, MD
}

Received: 19 July 2009/ Accepted: 11 August 2009/Published online: 26 September 2009

(C) Canadian Anesthesiologists' Society 2009

\section{To the Editor,}

We read with interest the excellent article by SiddikSayyid et al. ${ }^{1}$ describing the use of lidocaine $1.5 \mathrm{mg} \cdot \mathrm{kg}^{-1}$, rocuronium $0.3 \mathrm{mg} \cdot \mathrm{kg}^{-1}$, and remifentanil $2 \mu \mathrm{g} \cdot \mathrm{kg}^{-1}$ followed by propofol $2 \mathrm{mg} \cdot \mathrm{kg}^{-1} i v$ for tracheal intubation and reporting excellent intubating conditions in $90 \%$ of patients. The authors stated that this technique could be applied to brief surgical procedures or whenever the anticipated duration of surgery is uncertain. ${ }^{1}$ Using an ultrashort-acting opioid and a low dose of a non-depolarizing neuromuscular blocking drug (NMBD) is ideal for ambulatory surgery where rapid recovery is essential. There are also some patient groups that are especially sensitive to muscle relaxants, such as those with myasthenia gravis, myositis, or Guillain Barré syndrome, who might benefit from using this technique.

Siddik-Sayyid et al. did not include a control group in their study, and it remains unclear whether the tracheal intubating conditions would have deteriorated had rocuronium been omitted. However, Taha et al. used a similar medication sequence and dose regimen (lidocaine $1.5 \mathrm{mg} \cdot \mathrm{kg}^{-1}$, remifentanil $2 \mu \mathrm{g} \cdot \mathrm{kg}^{-1}$, propofol $2 \mathrm{mg} \cdot \mathrm{kg}^{-1}$ ) and reported that $84 \%$ of patients had excellent intubating conditions compared with $90 \%$ of patients in the Siddik-Sayyid et al. study. ${ }^{1,2}$ When deciding whether to use a muscle relaxant to facilitate tracheal intubation, one should take into account that omitting neuromuscular blocking drugs (NMBDs) can increase the frequency of poor intubating conditions. The recent Danish study of Lundstrom et al. found that avoiding NMBDs may increase the risk of difficult tracheal intubation, although further investigation is needed. ${ }^{3}$

A. Uvelin, MD $(\varangle) \cdot$ S. Stanisavljević, MD

Clinical Centre of Vojvodina, Novi Sad, Serbia

e-mail: auvelin@gmail.com
It is also important to bear in mind that rocuronium injection may cause severe pain. ${ }^{4}$ Therefore, whenever rocuronium is considered to be the NMBD of choice and when it is to be administered according to the "timing principle" (administration before the induction agent in order to decrease the effective onset time), lidocaine should be used prior to rocuronium.

The technique of lidocaine + low-dose rocuronium + remifentanil + propofol encompasses several issues. Lidocaine blunts the pressor response to laryngoscopy; it suppresses the cough reflex and decreases the remifentanil dose needed to improve tracheal intubating conditions and also prevents rocuronium injection pain. ${ }^{4,5}$ Remifentanil is effective as a co-induction agent, and it also blunts the pressor response. ${ }^{5}$ A low dose of rocuronium administered before the induction agent is usually sufficient to improve intubating conditions while having a short duration of action. Reducing the doses of remifentanil and propofol and prolonging the injection time of these drugs will help to ensure hemodynamic stability for the elderly and more medically complex patients during the induction of anesthesia.

Competing interests None declared.

\section{References}

1. Siddik-Sayyid SM, Taha SK, Kanazi GE, et al. Excellent intubating conditions with remifentanil-propofol and either low dose rocuronium or succinylcholine. Can J Anesth 2009; 56: 483-8.

2. Taha S, Siddik-Sayyid S, Alameddine M, et al. Propofol is superior to thiopental for intubation without muscle relaxants. Can J Anesth 2005; 52: 249-53.

3. Lundstrom LH, Moller AM, Rosenstock C, Astrup G, Gatke MR, Wetterslev $J$, et al. Avoidance of neuromuscular blocking agents may increase the risk of difficult tracheal intubation: a cohort study 
of 103,812 consecutive adult patients recorded in the Danish Anaesthesia Database. Br J Anaesth 2009; 103: 283-90.

4. Cheong KF, Wong WH. Pain on injection of rocuronium: influence of two doses of lidocaine pretreatment. Br J Anaesth 2000; 84: $106-7$.

5. Woods $A W$, Allam $S$. Tracheal intubation without the use of neuromuscular blocking agents. Br J Anaesth 2005; 94: 150-8.

\section{Reply}

We thank Dr. Uvelin and his colleagues for their interesting comments regarding our study. In a previous study, Taha et al. used the same medications (lidocaine, remifentanil, propofol) and found that $84 \%$ of patients had excellent intubating conditions. ${ }^{1}$ However, the time of drug administration and time to intubation differed between the two studies: In the study by Taha et al., midazolam $0.03 \mathrm{mg}$. $\mathrm{kg}^{-1}$ was given intravenously $5 \mathrm{~min}$ before induction of anesthesia. Patients then received lidocaine $1.5 \mathrm{mg} \cdot \mathrm{kg}^{-1}$ iv over $5 \mathrm{sec}$ followed by remifentanil $2 \mu \mathrm{g} \cdot \mathrm{kg}^{-1} i v$ over $30 \mathrm{sec}$, and propofol $2 \mathrm{mg} \cdot \mathrm{kg}^{-1} i v$ over $20 \mathrm{sec}$. Ninety seconds after propofol administration, laryngoscopy and tracheal intubation were attempted (total induction time $145 \mathrm{sec}$ ). In our study, no premedication was given. Patients in both groups received lidocaine $1.5 \mathrm{mg} \cdot \mathrm{kg}^{-1}$ over $5 \mathrm{sec}$. Immediately thereafter, patients in the rocuronium group received rocuronium $0.3 \mathrm{mg} \cdot \mathrm{kg}^{-1}$ over $5 \mathrm{sec}$, then remifentanil $2 \mu \mathrm{g} \cdot \mathrm{kg}^{-1}$ and propofol $2 \mathrm{mg} \cdot \mathrm{kg}^{-1}$ infused simultaneously over $30 \mathrm{sec}$. In the succinylcholine group, after receiving lidocaine, the remifentanil-propofol combination was given to study subjects in the same manner as in the rocuronium group, followed by succinylcholine $1.5 \mathrm{mg} \cdot \mathrm{kg}^{-1}$ administered over $5 \mathrm{sec}$. Laryngoscopy was performed $60 \mathrm{sec}$ after administration of remifentanil in the rocuronium group and $60 \mathrm{sec}$ after the end of administration of succinylcholine in the succinylcholine group. Total induction time in both groups was $100 \mathrm{sec}$. Small variations in either the technique or timing may achieve different results; tracheal intubating conditions depend not only on the anesthetic induction technique but also on the interval between drug administration and laryngoscopy, which ideally should coincide with the peak effect of each anesthetic drug. In the study by Taha et al., the induction-intubation interval was sufficiently long (145 sec $v s 100 \mathrm{sec}$ ) to allow optimal time for the anesthetic drugs to reach peak effect at the time of laryngoscopy. Had Taha et al. applied our induction sequence, a different incidence of excellent intubating conditions might have been observed. Furthermore, the results observed by Taha et al. are at variance with results from previous studies ${ }^{2,3}$ that compared intubating conditions using remifentanil $\left(2-4 \mu \mathrm{g} \cdot \mathrm{kg}^{-1}\right)$ and propofol without muscle relaxants. Excellent intubating conditions were achieved in only $50-60 \%$ of patients in those studies compared with $90 \%$ of patients in our report.

Other differences in study protocols may also account for the differences in the results between studies. Finally, since we did not include a control group, we agree that it is valid to question whether the intubating conditions would deteriorate had rocuronium been omitted. One can speculate that intubating conditions similar to those with succinylcholine may be achieved using a similar induction regimen without rocuronium.

Finally, we recognize that the dose of remifentanil and propofol we evaluated may be excessive in the elderly and in patients with cardiovascular or cerebrovascular disease. For these patients, reduced drug doses and/or slower administration rates are warranted.

Competing interests None declared.

\section{References}

1. Taha S, Siddik-Sayyid S, Alameddine M, et al. Propofol is superior to thiopental for intubation without muscle relaxants. Can J Anesth 2005; 52: 249-53.

2. Stevens $J B$, Wheatley $L$. Tracheal intubation in ambulatory surgery patients: using remifentanil and propofol without muscle relaxant. Anesth Analg 1998; 86: 45-9.

3. Klemola UM, Mennander S, Saarnivaara L. Tracheal intubation without the use of muscle relaxants: remifentanil or alfentanil in combination with propofol. Acta Anaesthesiol Scand 2000; 44: 465-9.

Sahar M. Siddik-Sayyid, MD

Marie T. Aouad, MD

American University of Beirut-Medical Center, Beirut, Lebanon 